\title{
Assessment of Defaulting from Directly Observed Treatment Short Course (DOTS) and Its Determinants in Benin City, Nigeria
}

\author{
Adolphus Inotu, Fekadu Abebe* \\ University of Oslo, Faculty of Medicine, Institute for Health and Society, Department of Community Medicine, \\ Oslo, Norway \\ Email: "Fekadu.abebe@medisin.uio.no
}

Received 6 December 2013; revised 10 January 2014; accepted 18 January 2014

Copyright (C) 2014 by authors and Scientific Research Publishing Inc.

This work is licensed under the Creative Commons Attribution International License (CC BY).

http://creativecommons.org/licenses/by/4.0/

(c) ()

\begin{abstract}
Background: Defaulting from Directly Observed Treatment Short Course (DOTS) is a big challenge to the effective control of TB. There are no published data on defaulting from DOTS in Benin City which necessitated this study to determine the rate of defaulting and identify factors that significantly contribute to defaulting in Benin City, Nigeria. Methods: This was a case control study from August to December 2011 of 1253 TB patients placed on DOTS in Benin City. The two DOTS centres used for the study were situated in University of Benin Teaching Hospital (UBTH) and Egor local government secretariat, both in Egor local government area (LGA) in Benin City. Out of 1253 patients registered on DOTS in the two study centres, 722 patients comprising of 172 defaulters and 550 non- defaulters were selected for the study using the inclusion and exclusion criteria. Logistic regression analysis was performed to determine association between independent variables and defaulting. Results: The default rate was $\mathbf{2 3 . 8 \%}$. Defaulting was significantly associated with: male sex (OR 3.05; 95\%CI 1.60 - 5.80), being married (OR 3.06; 95\%CI 1.34 - 6.99), a history of travel (OR 6.87; 95\%CI 3.19 - 14.80) and concomitant drug use with TB drugs (OR 1.95; 95\%CI 1.02 3.73). Conclusion: The default rate from DOTS in Benin City and the factors significantly associated with defaulting have given us some information initially unavailable about defaulting from DOTS in Benin City. TB control programmes taking these factors into consideration need to be done to promote compliance to treatment.
\end{abstract}

\section{Keywords}

DOTS Strategy; Defaulting; Tuberculosis Treatment; Nigeria

\footnotetext{
${ }^{*}$ Corresponding author.
} 


\section{Introduction}

Tuberculosis (TB) is a major public health problem globally. The prevalence, patterns of presentation and the mortality vary from one country to another and from one region of a country to another. These variations depend on prevailing social factors such as socio-economic status of the people [1], HIV/AIDS, malnutrition [2] [3], crowded living conditions, level of development of health infrastructures, quality of available control programmes and the degree of drug resistance to anti-tuberculosis drugs [4]. In 2012, there were an estimated number of 8.6 million incident cases of TB and 1.3 million died from the disease (940,000 deaths among people who were HIV negative and 320,000 among people who were HIV positive) [5]. Among these deaths, there were an estimated number of 170,000 from MDR-TB, a relatively high number compared with 450,000 incident cases of MDR-TB [5]. Nigeria ranks 4th among the 22 high burden countries of TB with an estimated number of 320,000 cases recorded every year resulting in more than 30,000 deaths annually [5].

In the Nigerian health system, services are provided at three levels namely: primary, secondary and tertiary. The local government areas (LGAs) provide the primary level of care; state governments provide the secondary level of care and provision of technical guidance to the LGAs, and the federal government is responsible for the tertiary level of care as well as policy formulation and technical guidance to the states. The private sector and non-governmental organizations, also provide considerable services at all the levels of health care; accounting for about $50 \%$ of health care delivery in the country [6]. From the onset of the National TB Control Programme (NTP), private (not-for-profit) mission health facilities and public (tertiary, secondary and some primary) health institutions have been involved in the TB control programme of the country [6]. Recently, few for-profit private health facilities have been incorporated into the programme through the public-private mix model [6]. Within the public sector, TB consultations, diagnostic, drugs and hospitalization services are provided free of charge. At the private facilities, TB diagnostic and treatment services are provided free-of-charge. However, all patients irrespective of their health problem visiting the facility pay administrative fees. Following diagnosis, TB patients admitted at the private hospitals are required to pay additional fees for accommodation and feeding (6).

Drug treatment for TB involves multiple drug regimens which must be taken for a minimum period of 6 months using the DOTS strategy adopted by World Health Organization (WHO) in 1995. In spite of the availability of potent anti-tuberculosis drugs, defaulting from treatment has been one of the major obstacles to the control of this disease. Interruption of treatment increases the risk of morbidity, mortality, spread of the disease and the cost to the control programmes [5].

In Nigeria, the prevalence of default has been shown to be $11 \%$ [7], this is high compared with WHO recommendation which states that the rate should be less than 10\% [5] [7]. Similarly, the emergence of multi-drug resistant tuberculosis (MDR-TB) has been linked to defaulting [5]. MDR-TB is an important cause of morbidity and mortality posing a greater challenge to effective control of this disease. Its management and treatment is very difficult and expensive thus overstretching the already strained resources for TB control in most developing countries [5] [7]. To the best of our knowledge, there are no published data on defaulting from DOTS in Benin City, thus, we embarked on this study to determine the default rate and identify associated factors with a view to making recommendations to improve DOTS programme in Benin City and Nigeria in general.

\section{Materials and Methods}

\subsection{Study Area and Population}

The study area is Benin City, the capital of Edo State in Southern Nigeria. It has a population of 1,147,188 people [8]. It is approximately 25 miles north of the Benin River and 200 miles by road east of Lagos, the commercial capital of Nigeria. It comprises mainly the Edo speaking ethnic groups of Bini, Ishan, Etsako, Owan and Akoko-Edo. Two DOTS centres in University of Benin Teaching Hospital (UBTH) and Egor Local Government secretariat were selected for the study. The two DOTS centres were situated in University of Benin Teaching Hospital (UBTH) and Egor local government secretariat both in Egor LGA in Benin City. DOTS programme started in UBTH August 2006 in the General Outpatient Clinic with 2 doctors and 7 nurses. Egor LGA has 9 DOTS centres, one each in UBTH and Egor secretariat and 7 in private clinics all situated within the 10 wards of the LGA. Most patients within the local government come to UBTH and Egor Local Government secretariat because TB drugs are given free except in the private clinics where patients are required to pay money. Secondly, there are easy access roads to these 2 DOTS centres. Thirdly, most patients who are suspected to have TB within 
the local government area are referred to these centres.

Treatment of TB in Benin City follows the guidelines from the National TB and Leprosy Control Programme of Nigeria. Patients suspected of having TB are required to do AFB test. Three sputum specimens are collected. TB is diagnosed based on the presence of at least 2 positive smear results, if the 3 samples are negative, radiological examination is done using chest X-ray in addition to clinical findings to ascertain the presence of TB. If TB is confirmed, patient is registered in the DOTS clinic where they are given drugs for 8 months according to WHO guidelines. First 2 months (intensive phase), patients take their medication on a daily basis in the DOTS centre in the presence of a designated health worker after which they collect their medication once monthly for 6 months (continuation phase). The recommended drug regimen for the intensive phase is isoniazid, rifampicin, ethambutol and pyrazinamide. In the continuation phase ethambutol and isoniazid are given. For retreatment cases, streptomycin is given for 3 months in the intensive phase in addition to isoniazid, pyrazinamide and rifampicin. During the course of the treatment, patients are required to produce 2 sputum samples for AFB test at the end of 2nd, 5th and 7th month to ascertain sputum conversion. If at the end of the 5th month sputum smear result is still positive, treatment is discontinued, patient is placed on category 2 regimens. Each DOTS centre has a focal person (supervisor) who oversees the programmatic activities of TB in the centre. The responsibilities among others involve the supervision of TB control activities, keeping up-to-date of accurate records and providing monthly reports to the state TB control officer. Patients are usually reminded on phone prior to commencement of continuation phase to collect their drugs and also in the event of missing any appointment.

This was a case control study of all TB patients placed on DOTS from August 2006 to December 2010. 1,253 patients were registered between these periods. TB register and treatment cards of patients were reviewed. Patients who defaulted formed the cases, while those who completed treatment made up the control group. Patients' socio-demographic characteristics, year of diagnosis and treatment outcome were collected from hospital records.

We used a set of inclusion and exclusion criteria based on WHO standard definitions of TB treatment outcomes in screening participants for the study.

The inclusion criteria used were: (1) TB patients who live within Benin City. (2) Patients registered in the 2 DOTS centres from August 2006 to December 2010. (3) Patients who defaulted after being on treatment for at least 4 weeks and whose treatment were interrupted for more than 8 weeks.

The exclusion criteria were: (1) TB patients who live outside Benin City. (2) Patients who defaulted after being on treatment for less than 4 weeks. (3) Patients whose contact information was incomplete. (4) Patients who died, transferred to other DOTS centres or had treatment failure. 722 patients comprising of defaulters $(n=172)$ and non-defaulters $(n=550)$ were finally selected for the study (Figure 1). One hundred and sixty three non-defaulters and ninety nine defaulters were recruited consecutively for interview from the study population of 722 patients. Contact tracing was facilitated by means of mobile phones and contact addresses. House to house interview was conducted using a semi-structured questionnaire. Information pertaining to patients' socio-demographic characteristics; TB treatment details; patients' related factors; and service provider factors were collected. They all formed the basis for the independent variables used in explaining the outcome variable (defaulter and non-defaulter). The questionnaire was pretested in one of the study centres. 10 patients were randomly selected ( 7 who completed treatment and 3 defaulters) as part of practical exercise to determine the quality of the questionnaire.

\subsection{Data Management and Analysis}

The data collected using questionnaire were double-checked to ensure consistency of information. Data were analysed using SPSS version 18 (SPSS Inc., Chicago, IL, USA). Frequency and distribution checks were used to access the range of values and identify missing data.

Univariate and multivariate logistic regression analyses were used to determine the association between independent variables and outcome variables with the odds ratio (OR) and 95\% confidence interval (CI) indicative of the strength of association. Variables were selected for the multivariate logistic regression analysis based on a $\mathrm{P}$ value $\leq 0.25$ from the univariate analysis bearing in mind each of the reference category. A two-sided $\mathrm{P}$ value $\leq 0.05$ was considered statistically significant. All candidate variables were included at once in the multivariate regression analysis to control for confounding effects. We did multiple univariate analyses using different reference categories from each independent variable to determine which output performs well in explaining the associations between the independent variables and defaulting. Fisher exact test was done if any cell had expected 


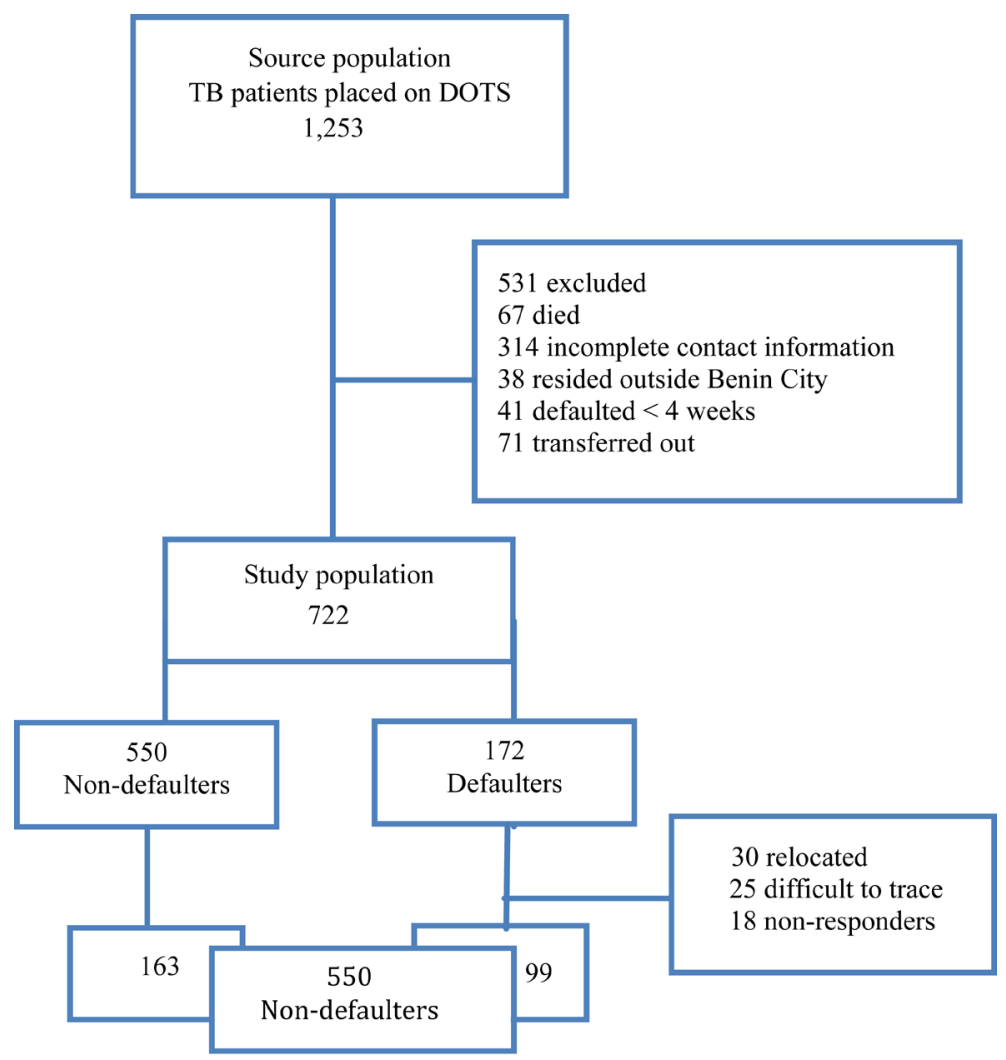

Figure 1. Sampling technique of TB patients placed on DOTS in the 2 study centres in Benin City.

cell count $<5$.

Ethical clearance for the research work was obtained from the Norwegain Regional Committee for Medical and Research Ethics, Southeast (Regionale Komite for Medisnk of Forksingsetikk for southeast, REK, Sør-øst) and also from the Ethics and Research Committee of University of Benin Teaching Hospital in Nigeria. Written informed consent was also obtained from the study participants before commencing interview.

\section{Results}

Of the 722 TB patients that made up the study population, 172 (23.8\%) defaulted and 550 (76.2\%) completed treatment. Similarly, there was an upward trend in default rate over the years from 2006 to 2009. The trend was $3.0 \%$ in 2006 to $29.3 \%$ in 2009 with a decline to $16.2 \%$ in 2010 (Figure 2). A majority of defaulters 59 (59.6\%) defaulted in the continuation phase of treatment while 40 (40.4\%) defaulted in the intensive phase. Tables 1 and 2 present the socio demographic characteristics of the study participants and univariate analysis of socio demographic factors with defaulting respectively.

The reasons for defaulting were a feeling of getting better (35.4\%), long distance to health facility (25.3\%), lack of money (10.1\%), medication side effects (5.1\%), condition worsened i.e. did not improve with the use of TB drugs (4\%), a feeling that hospital treatment will not cure the disease (2.0\%) and maternal leave (1.0\%). Patients relocating to other areas for greener pastures and business trips, family reunion in another city, funeral ceremony outside Benin City, seeking help from a spiritualist and herbalist were other reasons given by (28.8\%) of patients.

The factors independently associated with defaulting in the multivariate logistic regression analysis were male sex, high status occupation, being married, history of travel, use of TB drugs with other medications and occasional counseling by care provider (Table 3). Significant factors associated with defaulting were male sex (OR 3.05; 95\% CI 1.60-5.80), being married (OR 3.06; 95\% CI 1.34 - 6.99), history of travel (OR 6.87; 95\% CI 3.19 - 14.80) and concomitant use of TB drugs with other medications (OR 1.95; 95\% CI 1.02 - 3.73). 


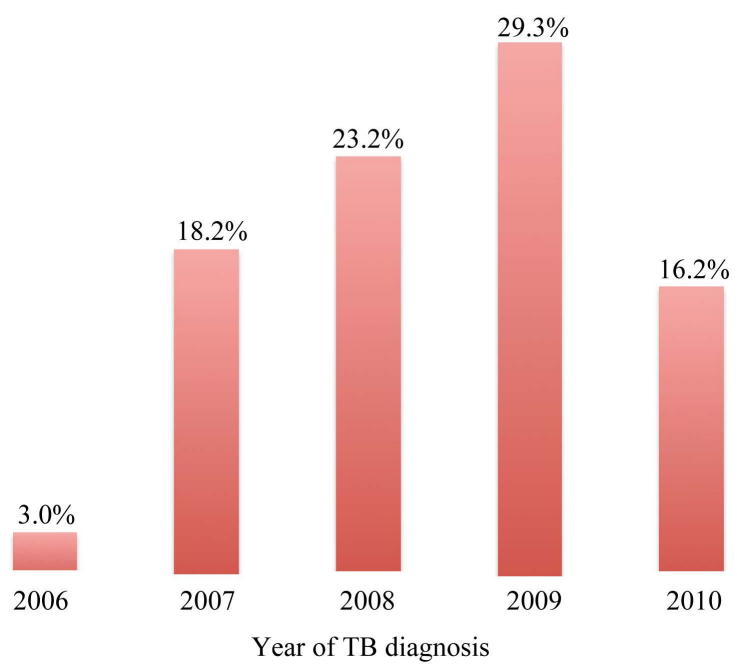

Figure 2. Bar chart showing default rate among TB patients placed on DOTS from 2006-2010.

\section{Discussion}

This current study documented a default rate of $23.8 \%$ among patients receiving directly observed treatment for TB in Benin City. WHO recommends that the default prevalence should be less than 10\% [5] [7]. WHO places high emphasis on achieving high compliance levels than finding new cases. Our finding is higher compared to studies in Spain [9] and Netherland [10] which documented a default rate of $1.8 \%$ and $10 \%$ respectively. In comparison with other Nigerian studies, it is relatively lower; $44.2 \%$ in Ilorin [11], 27\% in Ife [12] and 24\% in central part of Edo State [13]. One possible reason for lower default rate in the current study could be due to the use of mobile phones for reminding patients to collect drugs for the continuation phase (personal observation). The use of mobile phones in contact tracing is a novel approach that needs to be promoted. This can be done through the creation of communication network between patients, family members, local community and the health facility. With this, patients can be easily followed up and recalled back to treatment in any event of stopping treatment as evidenced from India [14] and Thailand [15]. It was noted also that patients were required to indicate their next of kin contact details in treatment cards at the point of registration to serve as an alternative means of tracing them. Another possible explanation for this could be linked to the implementation put in place at the initial stage of DOTS programme which started in 2006 in one of the study centres (UBTH). It is also possible that patients were not appropriately referred to centres closer to their places of residence. With the improvement in patient selection and deployment of permanent staff to the DOTS clinic, there was a reduction in default rate in 2010.

However in contrast to our study, a Nigerian study [16] found that there was a decline over the years from 1997 to 2001 in default prevalence. They attributed this to the better programme management in selecting patients; eligibility of patients for treatment was based on proximity to the TB centre. Referrals were made to other centres for patients who live outside the locality. We observed that majority of the defaulters $59.6 \%$ defaulted in the continuation phase of treatment. This is similar to studies in Nigeria [16], Ethiopia [17] and Singapore [18]. This may be attributed to the long duration of treatment and the feeling of wellbeing by patients in the course of treatment. However, some studies in Kenya [19], Hong Kong [20] and Brazil [21] have documented higher default rate in the intensive phase of treatment. Patients usually feel better shortly after initiation of treatment in the intensive phase because drugs used during this phase rapidly reduce the number of tubercle bacilli load. Thus, inadequately counseled patients may mistake the improvement in their health as cure. This study documented a feeling of improvement in health as a major reason for defaulting. Patients should be regularly counseled on the need to complete treatment irrespective of disappearance of TB symptoms. Lack of money and long distance to health facility were reported also as other major reasons for defaulting. Daily clinic attendance can put some financial strain on patients in terms of lost income from work and transportation cost to and from health facilities. TB drugs are administered to patients free in DOTS centres, but at certain times as observed 
Table 1. Socio-demographic characteristics of study participants in Benin City ( $\mathrm{N}=262)$.

\begin{tabular}{|c|c|c|}
\hline Variable & Count & Percentage (\%) \\
\hline \multicolumn{3}{|l|}{ Age } \\
\hline $0-15$ & 13 & 5.0 \\
\hline $16-31$ & 109 & 41.6 \\
\hline $32-47$ & 86 & 32.8 \\
\hline$\geq 48$ & 54 & 20.6 \\
\hline \multicolumn{3}{|l|}{ Sex } \\
\hline Male & 144 & 55.0 \\
\hline Female & 118 & 45.0 \\
\hline \multicolumn{3}{|l|}{ Marital status } \\
\hline Married & 141 & 53.8 \\
\hline Single & 121 & 46.2 \\
\hline \multicolumn{3}{|l|}{ Occupation } \\
\hline Student/unemployed & 83 & 31.7 \\
\hline Farmer/others & 25 & 9.5 \\
\hline Business & 116 & 44.3 \\
\hline Civil servants/professional & 38 & 14.5 \\
\hline \multicolumn{3}{|l|}{ Family size $^{\dagger}$} \\
\hline $1-4$ & 99 & 37.9 \\
\hline $5-8$ & 144 & 55.2 \\
\hline$>8$ & 18 & 6.9 \\
\hline \multicolumn{3}{|l|}{ Education } \\
\hline No formal education/primary & 42 & 16.0 \\
\hline Secondary/others & 130 & 49.6 \\
\hline Tertiary & 90 & 34.4 \\
\hline \multicolumn{3}{|l|}{ Monthly income* } \\
\hline$<18,000$ Naira $^{1}$ & 73 & 60.8 \\
\hline$\geq 18,000$ Naira & 47 & 39.2 \\
\hline \multicolumn{3}{|l|}{ Religion } \\
\hline Christian & 255 & 97.3 \\
\hline Muslim & 3 & 1.2 \\
\hline Traditional worshipper & 2 & 0.8 \\
\hline \multicolumn{3}{|l|}{ Ethnicity } \\
\hline Bini & 168 & 64.1 \\
\hline Ishan & 26 & 9.9 \\
\hline Igbo & 29 & 11.1 \\
\hline Others & 39 & 14.9 \\
\hline
\end{tabular}

${ }^{*} 142$ (54.2\%) missing cases because income does not apply to all patients and some refused to indicate their income. $\dagger 1$ (0.3\%) missing cases; ${ }^{1} \mathrm{US}$ Dollar $=158$ Nigerian Naira as at the time of writing this paper. 
Table 2. Univariate analysis between socio demographic factors and defaulting.

\begin{tabular}{|c|c|c|c|c|c|c|}
\hline Factor & Label & Non-defaulter & Defaulter & OR & $95 \% \mathrm{CI}$ & P-value \\
\hline \multirow[t]{4}{*}{ Age } & $16-31$ & 72 & 37 & 1.0 & & \multirow[t]{4}{*}{$0.616^{* *}$} \\
\hline & $0-15$ & 7 & 6 & 1.67 & $(0.52,5.32)$ & \\
\hline & $32-47$ & 50 & 36 & 1.40 & $(0.78,2.51)$ & \\
\hline & $\geq 48$ & 34 & 20 & 1.15 & $(0.58,2.26)$ & \\
\hline \multirow[t]{2}{*}{ Sex } & Female & 86 & 32 & 1.0 & & \multirow[t]{2}{*}{$0.001^{*}$} \\
\hline & Male & 77 & 67 & 2.34 & $(1.39,3.94)$ & \\
\hline \multirow[t]{3}{*}{ Education } & Secondary/others & 80 & 50 & 1.0 & & \multirow[t]{3}{*}{0.414} \\
\hline & No education/primary & 23 & 19 & 1.32 & $(0.65,2.67)$ & \\
\hline & Tertiary & 60 & 30 & 0.80 & $(0.46,1.41)$ & \\
\hline \multirow[t]{4}{*}{ Occupation } & Business & 65 & 51 & 1.0 & & \multirow[t]{4}{*}{0.090} \\
\hline & Student/unemployed & 51 & 32 & 0.80 & $(0.45,1.42)$ & \\
\hline & Farmer/others & 17 & 8 & 0.60 & $(0.24,1.50)$ & \\
\hline & Civil servant/professional & 30 & 8 & 0.34 & $(0.14,0.81)$ & \\
\hline \multirow{2}{*}{ Marital status } & Single & 86 & 35 & 1.0 & & \multirow{2}{*}{$0.006^{*}$} \\
\hline & Married & 77 & 64 & 2.04 & $(1.22,3.42)$ & \\
\hline \multirow{2}{*}{ Monthly income } & $<18,000$ & 52 & 21 & 1.0 & & \multirow{2}{*}{0.542} \\
\hline & $\geq 18,000$ & 31 & 16 & 1.28 & $(0.58,2.81)$ & \\
\hline \multirow[t]{3}{*}{ Family size } & $5-8$ & 87 & 57 & 1.0 & & \multirow[t]{3}{*}{0.373} \\
\hline & $1-4$ & 62 & 37 & 0.91 & $(0.54,1.54)$ & \\
\hline & $>8$ & 14 & 4 & 0.44 & $(0.14,1.39)$ & \\
\hline
\end{tabular}

${ }^{* *}$ Fisher exact test; ${ }^{*}$ Significant at $\mathrm{P} \leq 0.05$; OR =Odds ratio; $\mathrm{CI}=$ Confidence interval.

Table 3. Multivariate logistic regression analysis of determinant factors of TB treatment defaulting.

\begin{tabular}{lccc}
\hline Factor & OR & $95 \% \mathrm{CI}$ & P-value \\
\hline Male & 3.05 & $(1.60,5.80)$ & $0.001^{*}$ \\
Student/unemployed & 1.36 & $(0.56,3.30)$ & 0.495 \\
Farmer/others & 0.55 & $(0.17,1.77)$ & 0.316 \\
Civil servant/professional & 0.24 & $(0.08,0.70)$ & $0.009^{*}$ \\
Married & 3.06 & $(1.34,6.99)$ & $0.008^{*}$ \\
Transport cost $\geq 200$ & 1.21 & $(0.57,2.54)$ & 0.622 \\
No TB knowledge & 1.91 & $(0.48,7.62)$ & 0.357 \\
History of travel & 6.87 & $(3.19,14.80)$ & $<0.001^{*}$ \\
Concomitant drug use with TB drugs & 1.95 & $(1.02,3.73)$ & $0.045^{*}$ \\
Counseled on first visit only & 0.87 & $(0.44,1.71)$ & 0.680 \\
Counseled occasionally & 0.05 & $(0.01,0.28)$ & $<0.001^{*}$ \\
No privacy given & 1.93 & $(0.99,3.71)$ & 0.051 \\
\hline
\end{tabular}

*Significant at $\mathrm{P} \leq 0.05$. 
during this study, drugs were unavailable due to interruption in supply, patients were made to purchase drugs from pharmacy outlets. This might be challenging financially for some patients since most TB patients are from the lower economic status in the society as shown from previous studies [22] they are contended with both economic and health issues thus, there is a high probability of defaulting from treatment. Measures should be put in place to ensure a continuous uninterrupted supply of anti-TB drugs in health facilities. This is very important for the success of TB control programmes.

From the multivariate analysis, there was a significant association between male sex and defaulting. Male patients had three times the risk of defaulting from TB treatment compared to their female counterparts. This is consistent with reports from studies in Nigeria [23], Kenya [21], Malaysia [24] and Madagascar [25]. The Nigerian study [23] reported that male sex was a good predictor of poor treatment outcome. The reason for these could be attributed to the fact that in most societies, men are the bread winners in the family, they tend to leave home early for work in order to provide for their families and thus find it difficult to comply with daily clinic attendance especially during the intensive phase of treatment [18]. There is need for treatment programme to be made more flexible to accommodate such group of patients. The use of home visitor or DOT supporter to supervise the administration of TB drugs is a good alternative. A Chinese study [26] found that the use of local health workers in delivery drugs to patients at home was a good alternative in enhancing compliance.

Patients who were married had a higher risk of defaulting compared to those who were single. A possible explanation could be family responsibility and associated lack of money and time which may have reduced their attention to health care. Our finding is contrary to studies in Kenya and China where patients who were singles had higher risk of defaulting compared to patients who were married [19] [26]. However, our finding is similar to a study in India which indicated a statistically significant association between patients who were married and defaulting [27].

Taking business as the reference occupation, the odds of defaulting was lower with a high status occupation (civil servants/professional) compared to other occupations. This is similar to studies in Nepal [29] and Ethiopia [30] which indicated that patients who were unemployed and in low status occupation had higher risk of defaulting compared to those in high status occupation. It is expected that patients in a high status occupation have the required resources to cater for associated TB cost, by virtue of this there is a high probability that treatment will be completed.

We found that the concomitant use of TB drugs with other medications increased the risk of defaulting. A possible reason for this could be due to unwanted side effects associated with multiple administrations of drugs. A Russian study showed that the concurrent use of HIV medications with TB drugs increases the side effects associated with TB chemotherapy [30]. Combining antiretroviral and TB drugs means taking many tablets daily, this can be difficult and challenging to some patients.

Patients who had a history of travel during the course of treatment defaulted more compared to those who did not $(\mathrm{P}<0.001)$. Patients travelled mainly for economic reasons like search for good jobs and business trips. It is challenging for patients to combine daily clinic attendance with other economic issues. A study [31] on the predictors of defaulting found a significant association between a history of travel and defaulting. Similarly, a study in Kenya [19] indicated that from the 120 patients who did not complete treatment, 15 (12.5\%) attributed their defaulting to travelling away from treatment localities thus missing scheduled appointment or running short of drugs.

We found that patients who received occasional counseling about TB from service providers had a lower risk of defaulting compared to those who were counseled on each visit to the clinic, indicating that counseling has a negative implication on DOTS implementation in Nigeria. This observation is contrary to our expectations that more counseling would result in less defaulting. The significant association with defaulting is similar to a study [31] reporting a significant association between frequency of counseling and defaulting. That fewer numbers of patients defaulted after receiving occasional counseling compared to patients who received counseling on each visit might be due to differences in understanding and comprehending the information being given by health care workers.

\section{Conclusion}

The current study has provided some important information on which to improve future DOTS programme in Benin City and Nigeria in general. This study has documented that male patients, being married, a history of travel and the concomitant drug use with TB drugs significantly increased the risk of defaulting. We also found 
that among patients who defaulted, the feeling of getting better, long distance to health facility and lack of money were the main reasons for stopping treatment. Measures like the use of health visitor or DOTS supporter for patient follow up, continual service training for DOTS providers to improve and upgrade their competencies in health education and communication skills and also provision of incentives to reduce economic burden associated with TB treatment need to be considered. The use of mobile phone in DOTS implementation in Nigeria and elsewhere warrants further investigation.

\section{Competing Interests}

The authors declare that they have no competing interests.

\section{Acknowledgements}

This study was supported by the Department of Community Medicine, Institute of Health and Society, University of Oslo. We are grateful to the staff of DOTS centres in University of Benin Teaching Hospital and Egor Local Government Secretariat for their support during the field work.

\section{References}

[1] Kendall, E.A., Theron, D., Frank, M.F., et al. (2013) Alcohol Hospital Discharge, and Economic Risk Factors for Default from Multidrug Resistant Tuberculosis Treatment in Rural South Africa: A Retrospective Study. PLoS ONE, 8, e83480. http://dx.doi.org/10.1371/journal.pone.0083480

[2] Chisti, M.J., Ahmed, T., Pietroni M.A., et al. (2013) Pulmonary Tuberculosis in Severely Malnourished or HIV-Infected Children with Pneumonia: A Review. Journal of population Nutrition, 31, 308-313. http://dx.doi.org/10.3329/jhpn.v31i3.16516

[3] Hood, M.L. (2013) A Narrative Review of Recent Progress in Understanding the Relationship between Tuberculosis and Protein Energy Malnutriton. European Journal of Clinical Nutrition, 67, 1122-1128. http://dx.doi.org/10.1038/ejcn.2013.143

[4] Millet, J.P., Moreno, A., Fina, L., et al. (2013) Factors That Influence Current Tuberculosis Epidemiology. European Spine Journal, 4, 539-548. http://dx.doi.org/10.1007/s00586-012-2334-8

[5] World Health Organization (2013) Global Tuberculosis Control. WHO Report 2013, Geneva.

[6] Ukawaka, K.N., Alobu, I., Nweke, C.O. and Onyenwe, E.C. (2013) Health-Care Seeking Behavior, Treatment Delays and Its Determinants among Pulmonary Tuberculosis Patients in Rural Nigeria: A Cross-Sectional Study. BMC Health Services Research, 13, 25. http://dx.doi.org/10.1186/1472-6963-13-25

[7] World Health Organization (2012) Global Tuberculosis Report 2012, Geneva.

[8] Government Population Census of Nigeria, 2006

[9] Cayla, J.A., Rodrigo, T., Ruiz-Manzano, J., Caminero, J.A., Vidal, R., Garcia, J.M., et al. (2009) Tuberculosis Treatment Adherence and Fatality in Spain. Respiratory Research, 10, 121. http://dx.doi.org/10.1186/1465-9921-10-121

[10] Borgdoff, M.W., Veen, J., Kalisvaart, N.A., Broekmans, J.F. and Nagelkerke, N.D. (2000) Defaulting from Tuberculosis Treatment in the Netherlands: Rates, Risk Factors and Trend in the Period 1993-1997. European Respiratory Journal, 16, 209-213. http://dx.doi.org/10.1034/j.1399-3003.2000.16b05.x

[11] Salami, A.K. and Oluboyo, P.O. (2003) Management of Pulmonary Tuberculosis: A Nine Year Review in Ilorin, Nigeria. West Africa Journal of Medicine, 22, 114-119.

[12] Erhabor, G.E., Adebayo, R.A., Omodara, J.A. and Famurewa, O.C. (2003) Ten Year Review of Patterns of Presentation and Outcome of Pulmonary Tuberculosis in OAUTHC, Ile Ife, Nigeria. Journal of health science, 3, 34-39.

[13] Salami, T.A.T., Samuel, S. O., Eze, K.C. and Oziogbe, O.E. (2007) Tuberculosis in a Nigerian Teaching Hospital: Incidence and Pattern of Distribution. Tropical Journal of Health Science, 14, 26-30.

[14] Elangovan, R. and Arulchevan, S. (2013). A Study on the Role of Mobile Phone Communication in Tuberculosis DOTS Treatment. Indian Journal of Community Medicine, 38, 229-233. http://dx.doi.org/10.4103/0970-0218.120158

[15] Kunawararak, P., Pongpanich, S., Chantawong S., Pokaew P., et al. (2013) Tuberculosis Treatment with Mobile-Phone Medication Reminders in Northern Thailand. South East Asian Journal of Tropical Medicine and Public Health, 24, 1444-1451.

[16] Daniel, O.J., Oladapo, O.T. and Alausa, O.K. (2006) Default from Tuberculosis Treatment Programme in Sagamu, Nigeria. Nigerian Journal Medicine, 15, 63-67.

[17] Tekle, B., Mariam, D.H. and Ali, A. (2002) Defaulting from DOTS and its determinants in three districts of Arsi Zone 
in Ethiopia. International Journal of Tuberculosis and Lung Disease, 6, 573-579.

[18] Chee, C.B.E., Boudville, I.C., Chan, S.P., Zee, Y.K. and Wang, Y.T. (2000) Patients and disease characteristics and outcome of treatment defaulters from Singapore tuberculosis control unit: a one-year retrospective survey. International Journal of Tuberculosis and Lung Disease, 4, 496-503.

[19] Muture, B.N., Keraka, M.N., Kimuu, P.K., Kabiru, E.W., Ombeka, V.O. and Oguya, F. (2011) Factors Associated with Default among Tuberculosis Patients in Nairobi Province, Kenya: A Case Control Study. BMC Public Health, 11, 696. http://dx.doi.org/10.1186/1471-2458-11-696

[20] Chan-Yeung, M., Noertjojo, K., Leung, C.C., Chan, S.L. and Tam, C.M. (2003) Prevalence and Predictors of Default from Tuberculosis Treatment in Hong Kong. Hong Kong Journal of Medicine, 9, 263-268.

[21] Oliveira, V.L., da Cunha, A.J. and Alves, R. (2006) Tuberculosis Treatment Default among Brazilian Children. International Journal of Tuberculosis and Lung Disease, 10, 864-869.

[22] World Health Organization (1996) Group at Risk. WHO’s Report on the Tuberculosis Epidemics. WHO, Geneva, 42-55.

[23] Fatiregun, A.A., Ojo, A.S. and Bamgboye, A.E. (2009) Treatment Outcomes among Pulmonary Tuberculosis Patients at Treatment Centres in Ibadan, Nigeria. Annals of African Medicine, 8, 100-104. http://dx.doi.org/10.4103/1596-3519.56237

[24] Chuah, S.Y. (1991) Factors Associated with Poor Patient Compliance with Anti-Tuberculosis Therapy in Northwest Perak, Malaysia. Journal of Tuberculosis, 72, 261-264.

[25] Cormolet, T.M., Rakotomalala, R. and Rajaonarioa, H. (1998) Factors Determining Compliance with Tuberculosis Treatment in an Urban Environment, Tamatave, Madagascar. International Journal of Tuberculosis and Lung Disease, 2, 891-897.

[26] Xu, W., Lu, W., Zhou, Y., Zhu, L., Shen, H. and Wang, J. (2009) Adherence to Anti-Tuberculosis Treatment among Pulmonary Tuberculosis Patients: A Qualitative Study. BMC Health Service Research, 9, 169. http://dx.doi.org/10.1186/1472-6963-9-169

[27] Vijay, S., Balasangameswara, V, H., Jagannatha, P.S., Saroja, V.N. and Kumar, P. (2003) Defaults among Tuberculosis Patients Treated under DOTS in Bangalore City: A Search for Solution. Indian Journal of Tuberculosis, 50, 185196.

[28] Mishra, P., Hansen, E.H., Sabroe, S. and Kafle, K.K. (2005) Socio-Economic and Adherence to Tuberculosis Treatment: A Case Control Study in a District in Nepal. International Journal of Tuberculosis and Lung Disease, 9, 11341139.

[29] Shargie, E.B. and Lindtjørn, B. (2007) Determinants of Treatment Adherence among Smear Positive Pulmonary Tuberculosis Patients in Southern Ethiopia. PLOS Medicine, 4, 280-286.

[30] Fry, R.S., Khoshnood, K., Vdovichenko, E., Granskaya, J., Sazhin, V., Shpakovskaya, L., et al. (2005) Barriers to Completion of Tuberculosis Treatment among Prisoners and Former Prisoners in St. Petersburg, Russia. International journal of Tuberculosis and Lung Disease, 9, 1027-1033.

[31] Ayeh, C. (2011) Predictors of Tuberculosis Treatment Defaulting at Dangme West District, Accra, Ghana. http://dspace.knust.edu.gh:8080/jspui/bitstream/123456789/57/1/A3.pdf 